\title{
Performance Comparisons on Post Combustion Flue Gas Control Systems in Locally Available Power Plants
}

\author{
K. T. Jayasinghe
}

\begin{abstract}
In this study, author attempted to analyze and compare the performance of different flue gas emission control systems of selected thermal power plants in terms of standard flue gas monitoring data and proposed emission standards of stationary sources combustion systems introduced by the Central Environmental Authority (CEA) of Sri Lanka. This study, however, does not discuss any design specifications or theoretical phenomena of the selected system and focused on to present the data in more practical way.

Sixty five sets of data obtained during the last 4 years (including 2017) from 3 numbers of fossil fuel fired and 5 numbers of bio fuel fired power plants were considered. Thus the numbers of data sets per plant are not equal and depend on those monitoring requirements such as annual, bi annual or quarterly and plant commissioning period. Hence some plants are having more than 10 times repeated data sets and some are having only the limited number of data sets. Data monitoring were based on the United State Environmental Protection Agency [USEPA] approved test methods.

Electro Static Precipitators [ESP], Bag Filters [BF], Cyclone Separators [CS] and Wet Scrubbers [WS] are the different flue gas emission control systems incorporated in the selected bio fuel fired power plants. None of the selected fossil fuel fired power plants are incorporated in such devices for flue gas emission control system.

The outcomes of this study will therefore be important and useful to compare the performance of different flue gas emission control system with respect to the type of fuel, way of combustion, types of plant and the capacity of plant etc. In addition, those information might be useful when implementing the proposed emission standard for power plants in terms of reference oxygen levels and emission limits.

Finally the author tries to convince the best suitable flue gas emission control method/methods for stationary combustion systems in future development; not only the power plants, but also the other industrial combustion systems, such as steam boilers, furnaces, kilns etc. can be modified with the suitable flue gas cleaning system.
\end{abstract}

Keywords: Power plants, Fossil fuel, Bio fuel, Scrubbers, Cyclone Separators, Electro Static Separators, Bag Filters

\section{Introduction:}

Electrical energy demand of the country meets through mainly the hydro, thermal and other renewable energy sources. During the period of 2011 to 2015, the total annual energy generation has rapidly increased due to increase of population, industrial growth and major construction projects [ Figure 1.0].

Thus, the percentage annual electrical energy generation; by the mentioned energy sources have been escalated mainly due to unexpected climatic changes, since the hydro power generation acts as a system base load [Figure 2.0]. In addition to the climatic changes, almost all the hydro power sources have already been utilized, poor existing plant performances and high capital requirement for implementation of renewable energy projects (wind, solar) etc. are the other reasons causing for such variations.

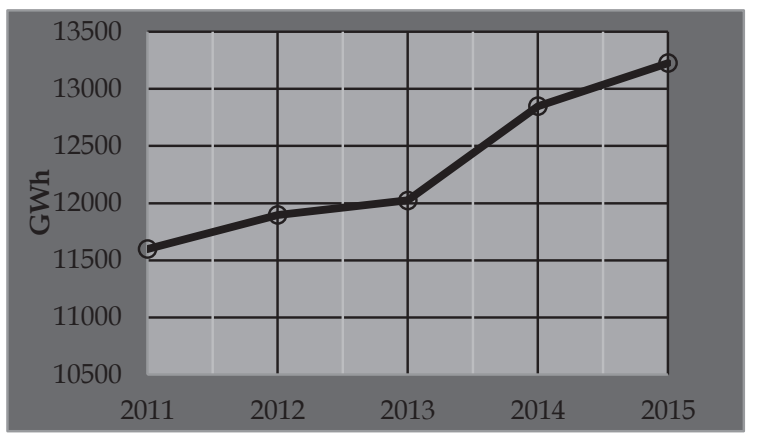

Figure 1.0 - Total Electrical Energy Generation 2011 to 2015. [Source - SLSEA Energy Balance 2015]

Eng. K T Jayasinghe, C Eng. M Sc (Energy), MIESL, Head of the Department - Energy \& Environmental Services, National Engineering Research \& Development Centre, NERDC, 2P/17B, Industrial Estate, Ekala, Ja Ela. 


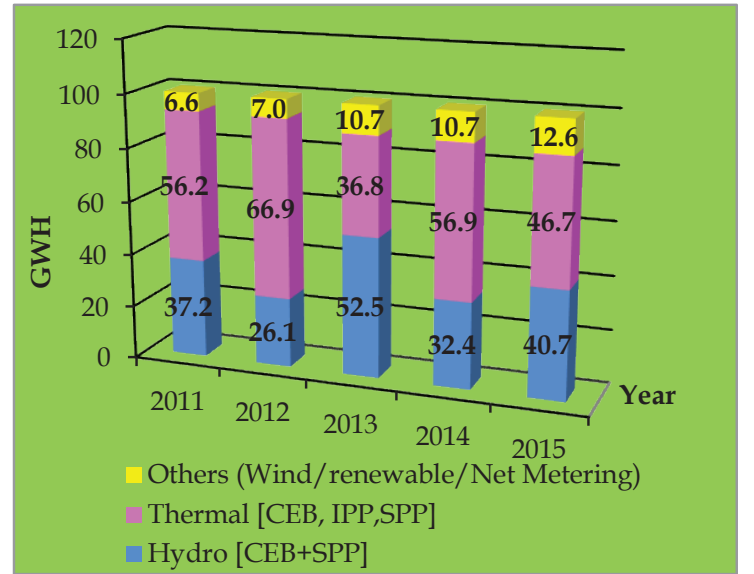

Figure 2.0 -Percentage Energy Generation by Different Sources.[Source - SLSEA Energy Balance 2015]

In this regard, setting up of thermal power plants have been increased (during the same period) in order to fulfill the national electrical energy demand [Figure 3.0].

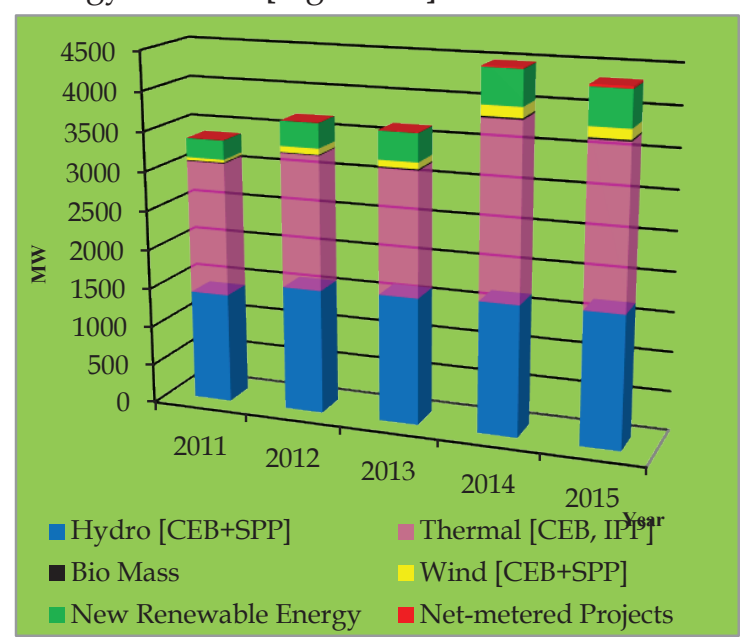

Figure 3.0 - Total Installed Capacities from 2011 - 2015[Source - SLSEA Energy Balance 2015].

The majority of thermal power plants have been operated by non-renewable energy sources such as coal and liquid fossil fuel. In addition to those, few bio fuels fired thermal power plants have recently added to the national power supply system. The total installed thermal energy capacities and the annual electricity generation based on the fossil fuel and the bio fuel are given in the Table 1.0.

In any instances, electricity generation by thermal power plants is not environmental friendly like electricity generation by renewable energy sources due to the relative quantities of flue gas emissions released to the environment. Such common emissions are noxious gases $\left(\mathrm{SO}_{x}\right.$, $\mathrm{NO})$, greenhouse gases $\left(\mathrm{CO}_{2}\right)$, unburned gases $\left(\mathrm{CO}, \mathrm{C}_{\mathrm{X}} \mathrm{H}_{\mathrm{Y}}\right)$ and Particulate Matter (PM). Those emissions can adversely affect, in different ways to the human health and the environment.

Table 1.0 - Total Thermal Energy Installed Capacities and Generation Capacities from 2011 to 2015

\begin{tabular}{lcccc}
\hline Year & \multicolumn{2}{c}{$\begin{array}{c}\text { Installed } \\
\text { Capacity }\end{array}$} & \multicolumn{2}{c}{$\begin{array}{c}\text { Generations } \\
\text { (GWH) }\end{array}$} \\
\cline { 2 - 5 } & $\begin{array}{c}\text { Fossil } \\
\text { Fuel }\end{array}$ & $\begin{array}{c}\text { Bio } \\
\text { Mass }\end{array}$ & $\begin{array}{c}\text { Fossil } \\
\text { Fuel }\end{array}$ & $\begin{array}{c}\text { Bio } \\
\text { Mass }\end{array}$ \\
$\mathbf{2 0 1 1}$ & 1690 & 13 & 6884 & 32 \\
$\mathbf{2 0 1 2}$ & 1695 & 11 & 8416 & 22 \\
$\mathbf{2 0 1 3}$ & 1575 & 16 & 4820 & 26 \\
$\mathbf{2 0 1 4}$ & 2213 & 20 & 7944 & 41 \\
$\mathbf{2 0 1 5}$ & 2028 & 20 & 6796 & 57 \\
\hline
\end{tabular}

[Source - SLSEA Energy Balance 2015]

In this regard, almost all the thermal power generating systems have been operated and maintained up to a certain extend as per the standardsby introducing respective flue gas cleaning system/mechanism either at pre combustion, during combustion or post combustion stage or stages. However, this study discussed only the systems used at the post combustion stage.

The performance of different flue gas emission control systems might be varied to each other, based on fuel types, plant capacities; combustion types etc. Hence this study included the evaluation of performance variations of different flue gas cleaning systems used in selected thermal power plants in terms of PM and toxic gases emission, types of fuels combustion and the system operations.

\section{Objectives and Methodology}

The main objective of this study is to compare the different flue gas emission control systems used inlocally operated selected power plants based on the monitored and analysed flue gas data as per the standard. This could be achieved through

Selecting locally available fossil fuels and bio fuels fired power plants.

Performing standard flue gas emission tests and converting those test results in to locally acceptable standards conditions (Temperature \& Pressure) and reference Oxygen levels.

- $\quad$ Repeating the emission tests quarterly, biannually or annually for the selected power plants (depending on the particular plant requirements) in order to minimize the errors occurred to the analysed data.

Investigating the system variations and effects such as fuel type, operating method, 
combustion type, plant category etc., of different combustion systems.

- Comparing the different flue gas emission control methods based on the summarised emission data in the view of environmental aspects.

\subsection{Power Plants Selection}

Eight numbers of different types flue gas cleaning systems in thermal power plants were selected based on the last four years emission data availability [1]. Out of those, 5 plants are bio mass combustion and the balance 3 plants are fossil fuel combustion. However, the coal power plant; the majority shared for electricity generation, has not taken in to considerations due to non-availability of monitored data. Selected plant details in terms of capacity, fuel used and the flue gas emission control systems attached are given in Table 2.0.

Table 2.0 - Selected Thermal Power Plants Details

\begin{tabular}{|c|c|c|c|}
\hline $\begin{array}{l}\text { Plant } \\
\text { Identity }\end{array}$ & Capacity & Fuel & $\begin{array}{l}\text { Final } \\
\text { Cleaning } \\
\text { Method } \\
\end{array}$ \\
\hline YPPK & $200 \mathrm{MW}$ & $\mathrm{HFO}$ & None \\
\hline КССРР & $165 \mathrm{MW}$ & NAP & None \\
\hline CPPJ & $8.0 \mathrm{MW}$ & $\mathrm{HFO}$ & None \\
\hline TPPT & $10 \mathrm{MW}$ & $\mathrm{PH}+\mathrm{WC}$ & Bag Filters \\
\hline TPРМ & $6.0 \mathrm{MW}$ & GC & ESP \\
\hline BENA & $2.5 \mathrm{MW}$ & $\mathrm{PH}$ & Dust Room \\
\hline NRPP & $2.0 \mathrm{MW}$ & $\mathrm{PH}$ & Water Jet \\
\hline AENA & $250 \mathrm{~kW}$ & PW & $\begin{array}{l}\text { Cyclone } \\
\text { Separator }\end{array}$ \\
\hline
\end{tabular}

NAP -Naphtha, HFO -Heavy Furnace Oil,

PH- Paddy Husk, WC - Wood Chips,

GC-Glideceria Chips, PW-Palm Wastes

\subsection{Monitoring Methods}

The instrumentations used and the monitoring methods are complied with the USEPA approved test methods as indicated in Table 3.0. The PM levels were monitored based on the “USEPA Test Method 5". USEPA Test Methods 1,2 and 4 are the supportive parameters monitoring methods for PM estimation. The other gaseous parameters were monitored based on the methods given in the Table 3.0 [2].
Table 3.0 - USEPA Test Methods for Stationary Sources Emission Monitoring

\begin{tabular}{|c|c|}
\hline Testing Parameter / Pollutant & Test Method \\
\hline $\begin{array}{l}\text { Sample and velocity traverses for } \\
\text { stationary sources }\end{array}$ & USEPA Method 1 \\
\hline $\begin{array}{l}\text { Stack gas velocity and volumetric } \\
\text { flow rate (Type S PITOT tube) }\end{array}$ & USEPA Method 2 \\
\hline $\begin{array}{l}\mathrm{CO}_{2} \text { and } \mathrm{O}_{2} \text { concentrations in } \\
\text { emissions from stationary sources }\end{array}$ & $\begin{array}{l}\text { USEPA Method } \\
3 \mathrm{~A}\end{array}$ \\
\hline Moisture content in stack gases [6] & USEPA Method 4 \\
\hline $\begin{array}{l}\text { Particulate } \quad \text { Matters } \quad(\mathrm{PM}) \\
\text { emissions from stationary sources }\end{array}$ & USEPA Method 5 \\
\hline $\begin{array}{l}\mathrm{SO}_{2} \text { emissions from stationary } \\
\text { sources }\end{array}$ & USEPA Method 6 \\
\hline $\begin{array}{l}\text { NOx emissions from stationary } \\
\text { sources }\end{array}$ & USEPA Method 7 \\
\hline $\begin{array}{l}\text { Visual determination of opacity of } \\
\text { emissions from stationary sources }\end{array}$ & USEPA Method 9 \\
\hline $\begin{array}{l}\mathrm{CO} \text { emissions from stationary } \\
\text { sources }\end{array}$ & $\begin{array}{l}\text { USEPA Method } \\
10\end{array}$ \\
\hline
\end{tabular}

\section{Literature Review}

\subsection{Local Standards Applicable}

The proposed atmospheric emission standard for stationary sources in Sri Lanka comprises of 17 regulations and 3 schedules. Those schedules are having numbers of "Parts" depending on the plant categories [3].

The Part I on Scheduled II describes the acceptable emission levels for the power generating units (except of the solid waste combustion) based on the plant type, plant capacities and the fuel types. In summarized, it can be considered that all the power generating units have to be maintained Particulate Matter $(\mathrm{PM})$, Sulphur Dioxide $\left(\mathrm{SO}_{2}\right)$, Nitric Oxides $\left(\mathrm{NO}_{\mathrm{x}}\right)$ and Opacity levels. However the levels depend on the fuel type and plant capacities [3].

\subsection{Emission Control Methods}

$\mathrm{PM}, \mathrm{NO} \times$ and $\mathrm{SO}_{2}$, emissions control of stationary combustion systems are often necessary to comply with environmental regulations. Techniques which are effective in reducing or eliminating those emissions can be subdivided into three general categories depending on which stage in the combustion process such as pre-combustion, combustion, and post-combustion [4].

Fuel processing methods at pre-combustion stage are very effective techniques to control emission. In these techniques fuels are cleaned 
or crude oil is refined, sulfur-laden particles and ash-bearing materials are removed, thereby making the fuel more desirable for applications where lower emissions are required.

Controlling the amount of $\mathrm{NOx}$ and $\mathrm{SO}_{2}$ that form during the combustion is also an effective technique for reducing emissions.

Although fuel processing and combustion controls play significant roles in emissions reduction, it is necessary to use post-combustion emission control techniques to remove $\mathrm{NO}_{X}$, $\mathrm{SO}_{2}$, and $\mathrm{PM}$ from the flue gas.

In this study, literature survey is limited to describe the post combustion technologies which are directly related to the study objective.

Post combustion techniques generally involve special equipment located downstream from the combustion system in order to clean the flue gas before releasing to the atmosphere [3]. Commonly available different flue gas cleaning mechanisms are,

- Mechanical Collectors

- Cyclone Separators

- Electrostatics Precipitators(ESP)

- Spray Towers

- Venturi Scrubbers and

- Bag houses (Fabric Filters)

However those selections are based on the emission type, plant type \& capacity, cost factor etc.

\subsubsection{Mechanical Collectors}

Mechanical collectors can be categorised as settling chambers and baffle chambers.

Settling chamber is a simple device consists of a large box having single or multiple chambers installed in the ductwork. The sudden expansion of size at the chamber heavy particles are trapped at the chamber bottom vessel due to the velocity

reduction

in the

chamber

[Figure

4.0].

Settling

chambers

are

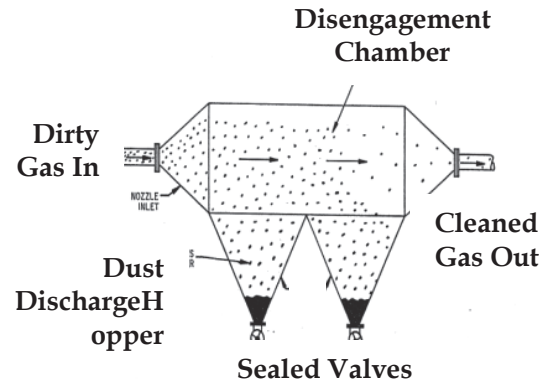

simple in

design

but those are seldom used as primary dust collectors because of low efficiency and excessive space requirement. In most systems, settling chambers are used as pre cleaners. A practical use is illustrated in Fig. 5.0.

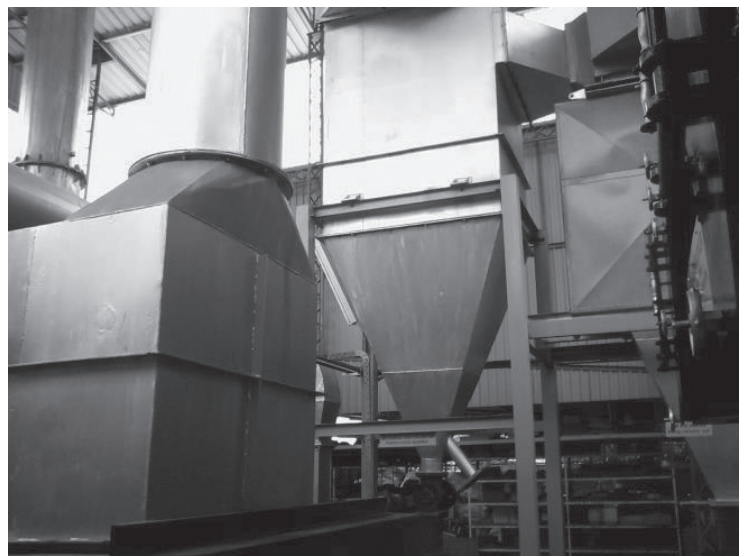

Figure 5.0 - Practical Used of SettlingChamber

Baffle chambers use a fixed baffle plate that causes the conveying gas stream to make a sudden change of direction. Large-diameter particles do not follow the gas stream but continue into a dead air space and settle. Baffle chambers are used as pre cleaners [4].

\subsubsection{Cyclone Separators}

Centrifugal collectors use cyclonic action to separate dust particles from the gas stream. In a typical cyclone, flue gas and particles are introduced tangentially into a cylinder so that a rotational movement is obtained. The centrifugal force created by the circular flow throws the dust particles toward the wall of the cyclone and begin to accumulate. These particles then move to the downward where the collecting hopper. The collected particles eventually discharge through an opening in the bottom of the hopper. A vortex finder is introduced along the vertical central axis of the cyclone in order to prevent particles in the incoming stream from contaminating the clean gas, separate them. The cleaned gas flows out through the vortex finder. Cyclones can be characterized by the particle cut diameter [4].

Cyclones are adequate for PM control when emission regulations are not restricted areas and when firing methods produced larger particles. However in many practices cyclones; alone the flue gas cleaning systems are no longer being used. Cyclone separators are more effective on particles larger than $10 \mu \mathrm{m}$ because collection efficiency drops dramatically as the particle size decreases [Figure 6.0].

Figure 4.0 - Settling Chamber's Sketch 


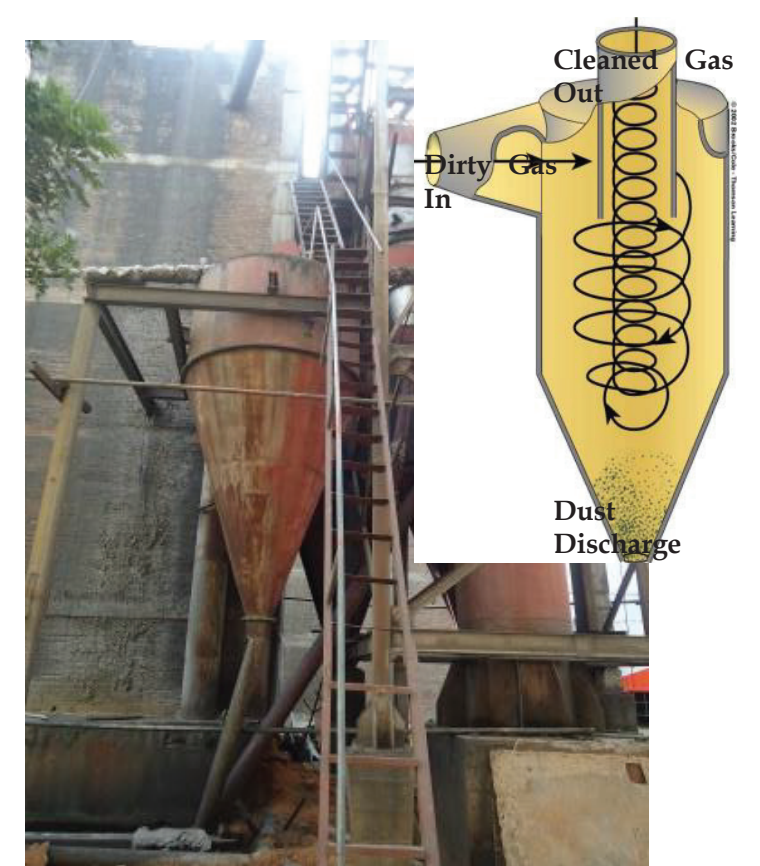

Figure 6.0 - Cyclone Separator for Flue Gas Cleaning

Multiple-cyclone separators consist of a number of small-diameter cyclones, operating in parallel and having a common gas inlet and outlet. Multiple-cyclone separators are more efficient than single cyclones because they are longer and smaller in diameter. The longer length provides longer residence time while the smaller diameter creates greater centrifugal force. These two factors result in better separation of dust particulates. The pressure drop of Multiplecyclone separators collectors is higher than that of single-cyclone separators[Figure 7.0].

Figure 7.0 - Practical use of Multiple Cyclone

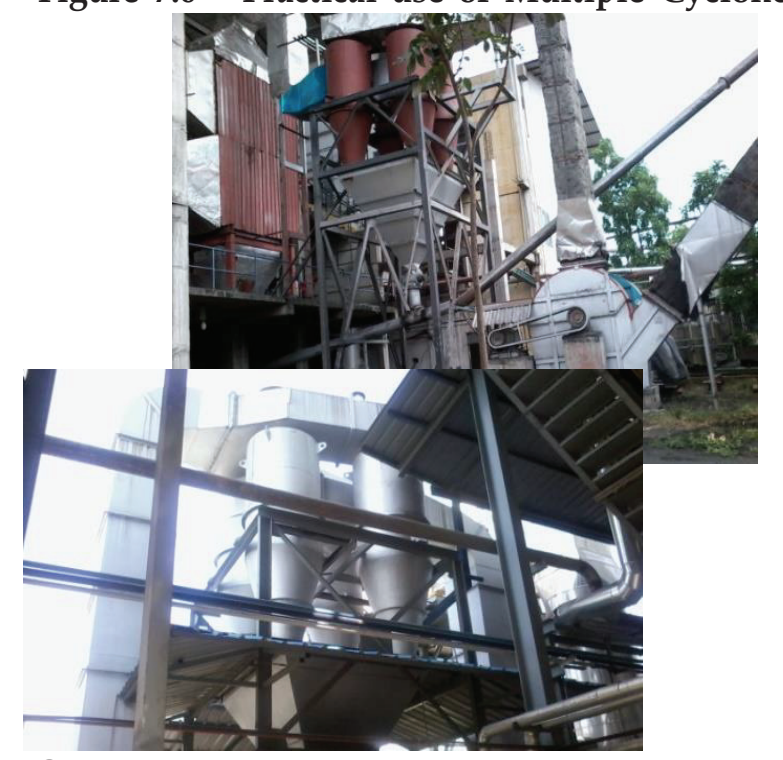

Separators

Secondary air flow separator cyclones uses a secondary air flow, injected into the cyclone to increase the speed of the cyclonic action making the separator more efficient; to intercepts the particulate before it reaches the interior walls of the unit; and to forces the separated particulate toward the collection area. The secondary air flow protects the separator from particulate abrasion and allows the separator to be installed horizontally because the separation of particle does not depend upon the gravity.

\subsubsection{Fabric Filters}

Fabric filter consists of a long, vertically supported, small-diameter bag. When several of these filters are arranged in a gas-tight enclosure located between the boiler and the stack, the entire assembly is commonly referred to as a bag-house. In operation, flue gas enters the baghouse and then it sent into either the inside or the outside of the individual fabric filters. After the flue gas passes through the fabric, it flows out of the bag-house and toward the stack. ThePM that dislodges from the filter material falls into a hopper at the bottom of the baghouse where it is removed and transported to a storage area [Figure 8.0].

Figure 8.0 - Fabric Filters Sketch [4]

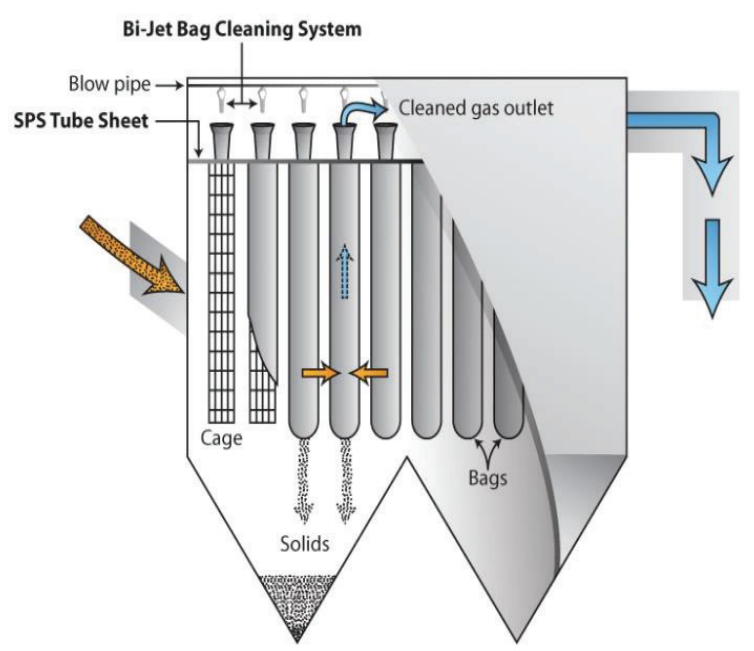

In operation, the dust-cake is periodically removed by shaking the bags, reversing air flow through the bags, or subjecting the bags to a high-pressure pulse of air. Flexing action during cleaning influences bag life, but advances in fabric technology and surface finish have enhanced their longevity and improved their emissions control potential. Newer fabrics made with synthetic materials have an improved service life, superior resistance to chemical attack, and better dust release properties.

The bags can be made out of woven or felted cotton, synthetic, or glass-fibre material in either a tube or envelope shape. Fabric filters are very effective devices for separating dry PM from flue gas. Woven fiberglass with an upper 
operating temperature of $500^{\circ} \mathrm{F}$ is a material commonly used to make bags for use as fabric filters. A typical bag has a diameter up to $12 \mathrm{in.}$ and a length that varies up to $36 \mathrm{ft}$.

Fabric filters are capable of removing more than $99.9 \%$ of the PM in a flue-gas stream. For these reasons, they are often considered the best available control technology for reducing PM emissions. A practical used of bag house for gas cleaning is illustrated in Figure 9.0.

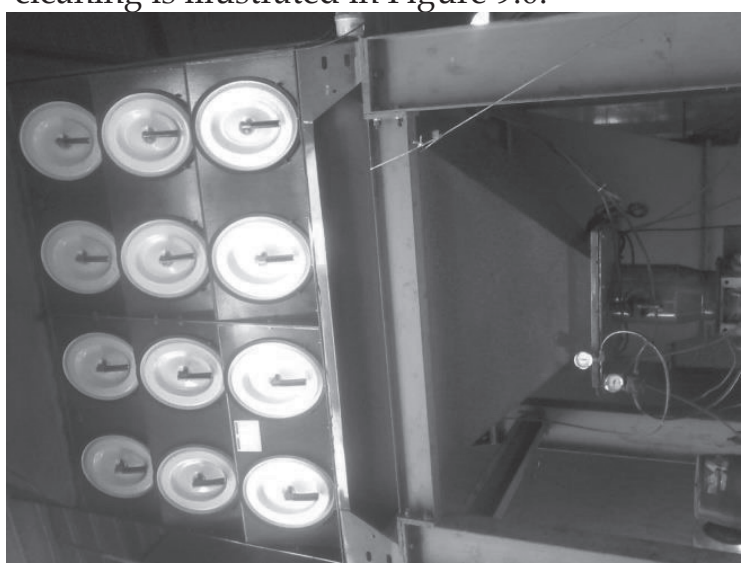

Figure 9.0 - Practical use of Bag House

\subsubsection{Selective Catalytic Reductants (SCR)}

SCR uses a catalyst and a reductant (Ammonia gas, $\mathrm{NH}_{3}$ ) to dissociate $\mathrm{NO}_{x}$ to $\mathrm{N}_{2}$ gas and $\mathrm{H}_{2} \mathrm{O}$ vapour. In practice, Ammonia injection pipes, nozzles, and mixing grids are located upstream from the catalyst chamber. After a dilute, Ammonia-Air mixture is injected into the flue gas stream, dispersion occurs, and the catalytic reaction is completed within the catalyst chamber [Figure 10.0].

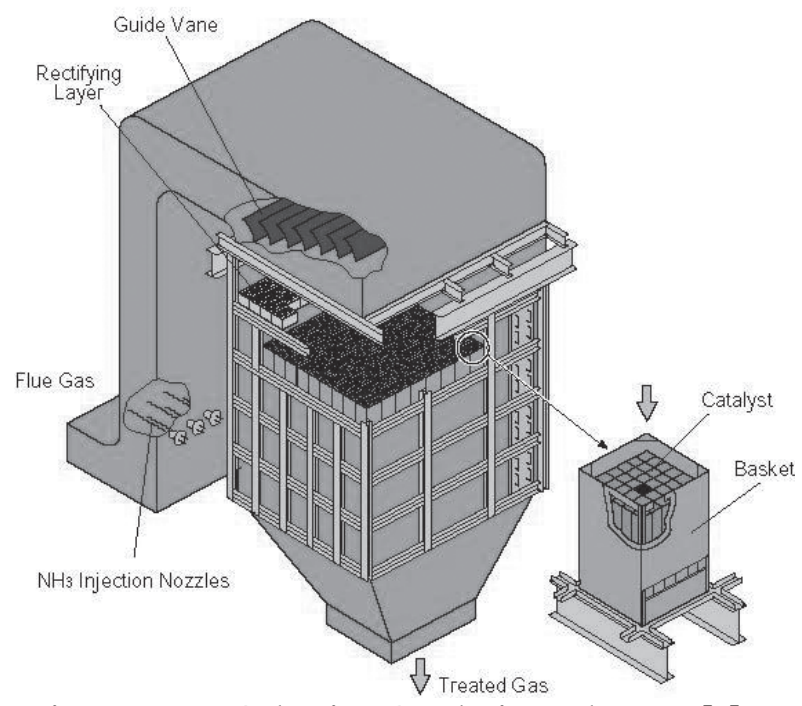

Figure 10.0 - Selective Catalytic Reductant [4] This technique is commonly used where high (70\% to $90 \%)$ NOx removal efficiencies are required. Use of SCR can be effective for boilers that burn a variety of fuels, including natural gas, oil, coal, and wood.

A variety of catalyst shapes and formulations are available for use in the SCR process. Two leading shapes are honeycomb and plate.

Catalyst selection is based on the resistance to toxic materials, abrasion, thermal cycling, oxidation of $\mathrm{SO}_{2} \& \mathrm{SO}_{3}$, plugging and, mechanical strength. Catalysts can be used where exhaust gas temperatures range between $350^{\circ} \mathrm{F}$ and $1,200^{\circ} \mathrm{F}$, but they are typically designed to operate within a range of $450^{\circ} \mathrm{F}$ to $850^{\circ} \mathrm{F}$. Optimum performance generally occurs between $650^{\circ} \mathrm{F}$ and $840^{\circ} \mathrm{F}$ depending on the fuel. Operation above this temperature range can reduce the effectiveness of certain catalysts, and operations at lower temperatures increase the likelihood of Ammonium Sulphate formation within the catalyst bed. The operating life of a catalyst bed is often exceeds 2 years. After the life time, an additional catalyst must be added, or the bed must be replaced.

\subsubsection{Electro Static Precipitators (ESPs)}

Removal of PM suspended in flue gas can be accomplished by electrically charging the particles in a device known as an ESP. The unit consists of a series of vertical collector plates with electrodes centrally located between the plates. When the plates are connected to an electrical ground and the electrodes are subjected to a high-voltage negative electrical charge, the particles take on a negative charge and begin migrating toward the positively charged collector plates. As flow continues, particles begin accumulating on the collector plate surfaces[Figure 11.0].

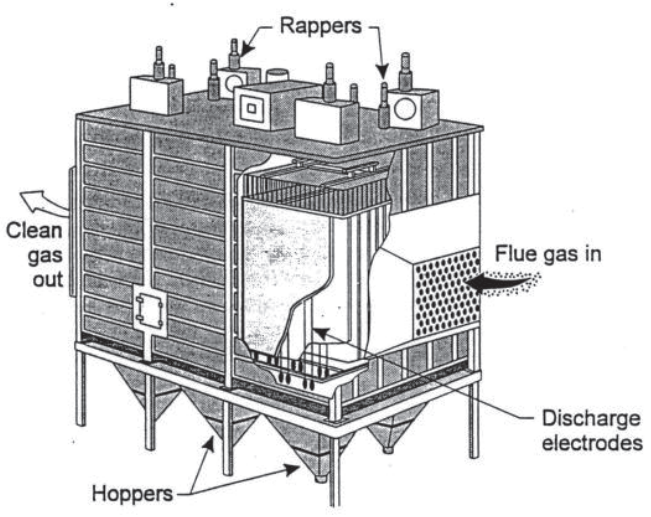

Figure 11.0 - Sketch of an ESP [5]

Eventually, a layer of particles builds must be removed. The popular method for removing the accumulated dust is rapping the plates. This 
sudden impact causes the particles to dislodge from the plates and fall into a hopper located at the bottom of the ESP [5].

There are two basic configurations for ESPs such as weighted wire and collector plate types. In the weighted-wire design, wires serve as the electrodes. These wires are suspended from a roof-mounted electrical distribution system. Weights attached to the bottoms of the wires ensure that the wires remain straight and vertical. The collector plates, which may be as long as $50 \mathrm{ft}$., are hung in rows like curtains at 12 to $16 \mathrm{in}$. on centres. The alignment of the electrodes and collector plates must be maintained within tight tolerance with uniform electrical field and no electrical arcing for optimum performance. Failure of the wire due to electrical arcing or other reasons is a recurring problem that results in performance deterioration of ESP [5].

In the rigid-frame and rigid-electrode designs, strips of proprietary electrodes are supported by a structural framework that maintains the required alignment. The rigid-frame and rigidelectrode designs are more rugged with higher equipment reliability. All ESPs include a large, gas-tight metallic housing that is insulated to prevent heat loss. Collection efficiencies of welldesigned ESPs can be $99.6 \%$ or higher, but it must be recognized that removal efficiency varies depending on the flue-gas loading and the design of the ESP.Fig.12.0 illustrates a practical use of ESP in power generating system.

\section{Figure 12.0 - Practical use of ESP in Power}

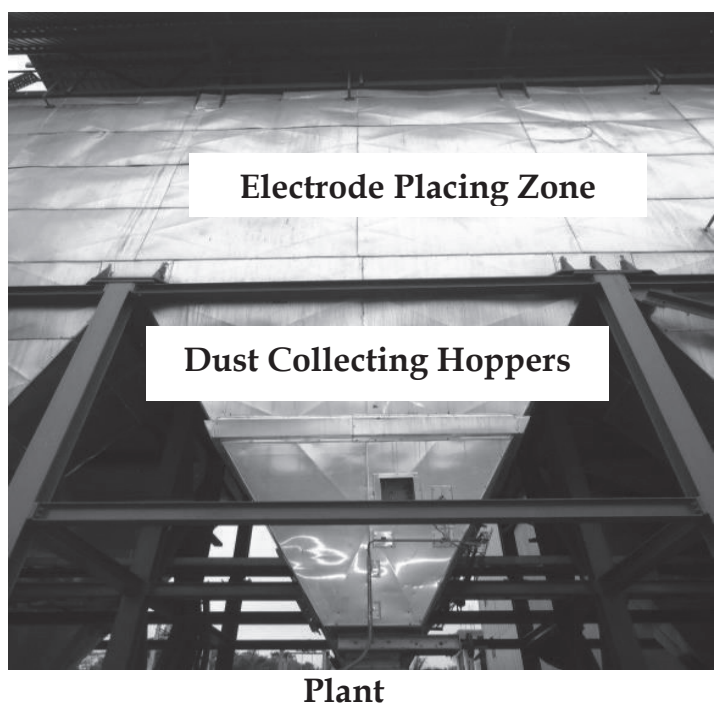

\subsubsection{Wet Scrubbers}

A wet scrubber is an air pollution control device that removes PM and acid gases from waste gas streams of stationary point sources through the impaction, diffusion, interception and/or absorption of the pollutant onto droplets of liquid. Wet scrubbers can be operated either counter current or co-current methods [6].

The liquid containing the pollutant is then collected for disposal PM in flue gas can be removed using wet scrubber by allowing the flue gas to flow through an atomized water stream like mist or fog. Then the particles in the flue gas collide with water and become entrained in the liquid droplets. These droplets fall to the lower chamber due to gravity. The sludge formed is sent to the settling pond or effluent treatment plant [ Figure 13.0].

Figure 13.0 - Practical use of Wet Scrubber

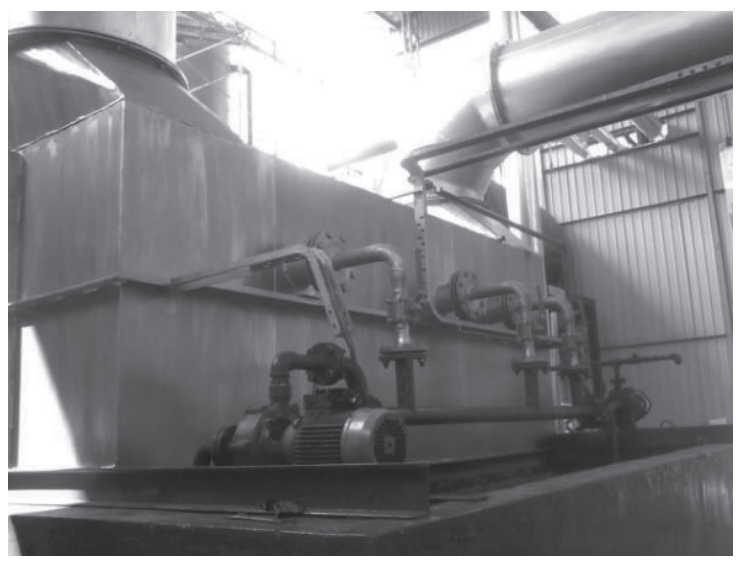

Wet scrubbers are particularly useful in the removal of PM with the following characteristics:

- Sticky and/or hygroscopic materials (materials that readily absorb water)

- Combustible, corrosive and explosive materials

- Particles which are difficult to remove in dry form

- PM in the presence of soluble gases; and in waste gas streams with high moisture content.

Venturi scrubbers are the high-pressure-drop wet scrubber method. Both types of wet scrubbers are effective for removing PM and certain gases which are soluble in water.[Figure 14.0].

Collection efficiencies of wet scrubbers vary with the particle size distribution of the waste gas stream and scrubber type. The efficiency range is from $99 \%$ for venturi scrubbers to 40 $60 \%$ for simple spray towers [6]. 

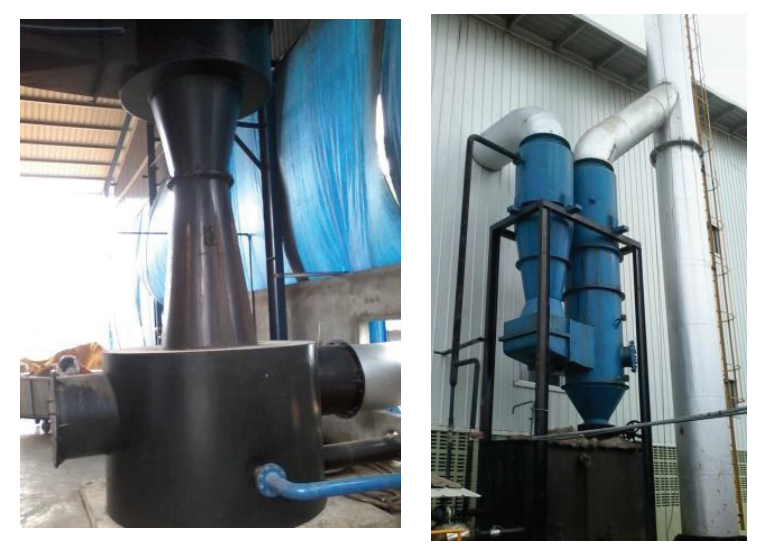

Figure 14.0 - Practical use of Venturi Scrubber

\section{Data Analysis of Selected Power Plants}

Fiftysets of flue gas monitoring data of eight power plants; discussed in the Table 2.0, were considered in this study. The average values of data sets of particular power plants are considered as the final results for evaluation.

\subsection{Stack Temperature Variations}

Stack temperature variations of selected power plants are illustrated in Fig. 15.0.

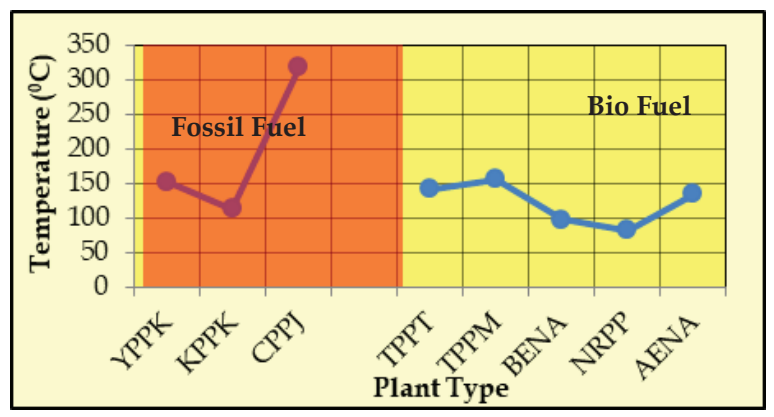

Figure 15.0 - Stacks Temperatures Variations

Figure 15 shows that the temperatures of fossil fuel fired power plants are relatively higher than the stack temperatures of bio fuel combustion power plants. The lower flue gas temperature of bio fuel power plants is due to installation of flue gas cooling systems (WS). Further two fossil fuel fired power plants are having low stack temperatures. Because those chimney heights are more than $40 \mathrm{~m}$ and flue gas gets self-cooling while travelling to the sampling ports.

\subsection{Oxygen and Excess Air Variations}

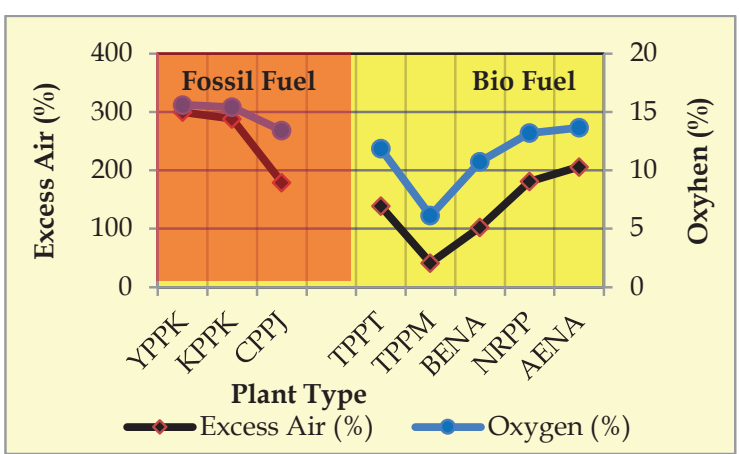

Figure 16.0 - Oxygen and Excess Air Variations of Selected Power Plants

Figure 16.0 shows that the Oxygen contents in flue gas of fossil fuel combustion power plants are relatively higher than the Oxygen contents in flue gas of bio fuel combustion power plants. When the Oxygen content is high, the relative excess air content is also high. The under mentioned reasons can be considered such variations. Further, the higher Oxygen content in flue gas might be affected, when converting the measured gaseous parameters to the standard reference Oxygen level (3\%).

None of the fossil fuel power plants has introduced flue gas cleaning mechanism at post combustion stages.

Excessive induce flow required to maintain the stack draft pressure, since the stack heights of particular power plants are more than $25 \mathrm{~m}$.

The Oxygen and related excess air contents in flue gas of ESP and BF introduced bio fuel combustion power plants are relatively low and close to the reference Oxygen in such types of combustion systems (i.e.6\%). The under mentioned reasons can be considered for such variations.

- Flow restrictions when the flue gas passes through the cleaning devices.

- $\quad$ Sufficient flue gas retention time inside the travelling path.

The Oxygen and related excess air content in flue gas of bio fuel combustion power plants; which have not incorporated in ESP or bag filters, are higher than the combustion power plants incorporated in ESP or bag filters. But values are lower than the considered fossil fuel power plants. The under mentioned reasons can be considered for such variations.

Stack heights are relatively low. Hence, maintained draft pressure is low. 
- $\quad$ Flow restrictions are less, since flue gas passes only through the cyclone separators.

\section{3 $\mathrm{CO}_{2}$ and $\mathrm{CO}$ Variations}

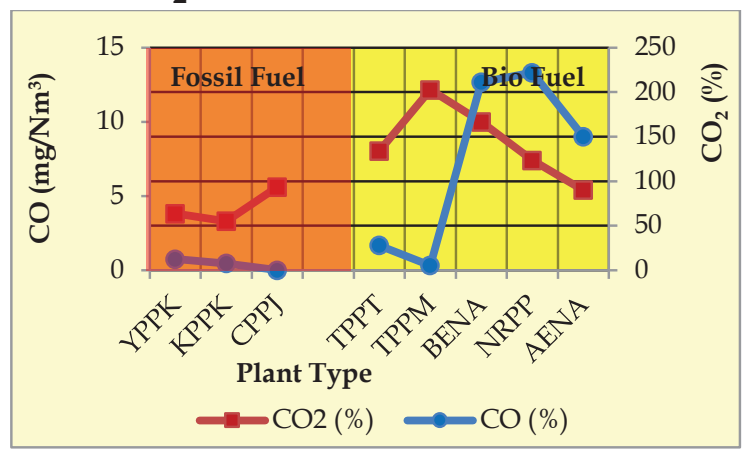

Figure 17.0 - $\mathrm{CO}_{2}$ and $\mathrm{CO}$ Variations of Selected Power Plants

Figure 17.0 shows that the $\mathrm{CO}$ and $\mathrm{CO}_{2}$ content in bio fuel combustion power plants are comparatively higher than those contents in fossil fuel power plants. The under mentioned reasons can be considered such variations.

- Variations of fuel qualities; moisture, volatiles etc.

- Uneven combustion properties; fuel charged, air inlet etc.

\section{4 $\mathrm{SO}_{2}$ and $\mathrm{NO}_{x}$ Variations}

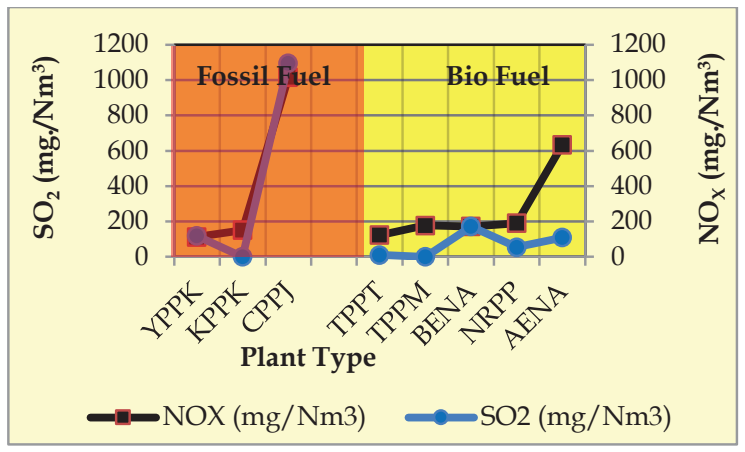

Figure $18.0-\mathrm{SO}_{2}$ and $\mathrm{NO}_{\mathrm{x}}$ Variations of Selected Power Plants

Figure 18.0 shows that the $\mathrm{SO}_{2}$ contents in flue gas of HFO fuel combustion power plant is relatively higher than the $\mathrm{SO}_{2}$ contents in flue gas of other fossil fuel combustion power plants. $\mathrm{SO}_{2}$ content in flue gas of bio fuel combustion power plants are relatively low.

The $\mathrm{NO} x\left(\mathrm{NO}+\mathrm{NO}_{2}\right)$ contents in flue gas of fossil fuel combustion power plant having stack temperatures above $300{ }^{\circ} \mathrm{C}$ are relatively higher than the $\mathrm{NO}^{\mathrm{x}}$ contents in flue gas of other fossil fuel and bio fuel combustion power plants. The reason might be the thermal $\mathrm{NO}_{x}$ formed at high temperature.

\subsection{Particulate Matter Variations}

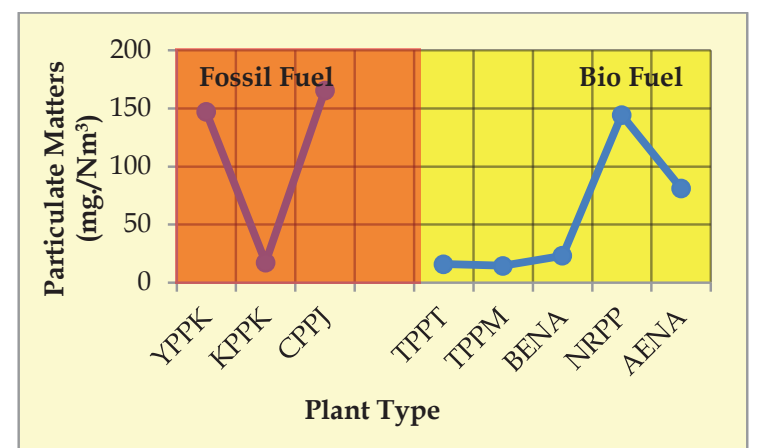

Figure 19.0 - Measured PM Variation of Selected Power Plants

Figure 19.0 shows that the PM contents in flue gas of power plants having ESP and bag filters are very low compared with the other power plants. However, measured PM levels of all the power plants are within the range of acceptable local standards.

\section{Conclusion}

The under mentioned conclusions can be made as the outcome of this study. Reference Oxygen level of the proposed standard for fossil fuel fired power plants has to be reconsidered, since the Oxygen content in flue gas of such type of power plants have been exceeded 12\%. ESP and bag filters incorporated with the flue gas cleaning systems of power plants are more effective than the considered other flue gas cleaning systems. Flue gas having high excess air and temperature would be the reason to form Nitric Oxides $\left(\mathrm{NO}_{\mathrm{x}}\right)$. Nitric Oxides $(\mathrm{NO})$ content in flue gas of the power plants incorporated with wet scrubbers presented the lower values than the other selected power plants. $\mathrm{SO}_{2}$ content in flue gas of the power plants incorporated with wet scrubbers presented the lower values than the other selected power plants since $\mathrm{SO}_{2}$ dissolved in water.

\section{Discussion}

Three bio fuel fired power plants are having only couple of data sets, because monitoring is done annually. Out of them, one power plant has recently set up and the other two have started the monitoring after implementing the proposed emission standards. Hence, analysed data might be affected by limited data obtained those power plants due to variations of combustion properties such as fuel type, size, moisture etc.

One fossil fuel fired power plant has only three data sets, since the monitoring is based on the 
annual and it has recently started the operations. Hence, those limited data sets might be affected to the analysed data. Measured $\mathrm{SO}_{2}, \mathrm{NO} x$ and PM levels of this power plant have been recorded the higher values than the selected other power plants. The other power plants analysed data are having more than five times monitoring data and can be confirmed that the obtained data are more accurate.

The measured Oxygen levels [Figure 11.0] of flue gas in fossil fuel fired combustion power plants were more than $12 \%$. Higher percentage of Oxygen contents in flue gas might be affected to the standard reference Oxygen level of such type of fuel combustion systems (i. e. 3\%).

The measured Oxygen levels [Figure 11.0] of flue gas in bio fuel fired combustion power plants have been varied from $6 \%$ to $13 \%$. The higher Oxygen levels in flue gas might be affected when converting the measured PM and other gaseous parameters to the standard reference Oxygen level of such type of fuel combustion systems (i. e. 6\%).

\section{Acknowledgement}

The author wishes to thank Eng. Shavindranath Fernando, Chairman, NERDC, and Eng. D D Ananda Namal for granting permission to publish this paper. Author also appreciate the professional inputs given by Eng. Nandana Edirisinghe, Research Fellow, NERDC by way of editing the paper.

\section{References}

1. Stationary Combustion Sources Emission Test Reports. National Engineering Research \& Development Centre - 2015-2017.

2. Environmental Protection Agency, U.S. (EPA), "Stationary Source Control Techniques Document for Fine Particulate", EPA Document No. EPA452/R-97-001, Office of Air Quality Planning and Standards, Research Triangle Park, NC, September 30, 1997.

3. Proposed Environmental Standards for Stationary Combustion Sources; Central Environmental Authority, Sri Lanka. Schedule II - Part I to of National Environmental Act No. 47 of 1980.

4. Davis, W.T. Ed., Air Pollution Engineering Manual (2ndEdition), Air and Waste Management, John Wiley \& Sons, Inc., New York, 2000.

5. Daniel Mussatti U.S. Environmental Protection Agency Research Triangle Park, NC 27711 and
Paula Hemmer E.H. Pechan\& Associates, Inc. 3622 Lyckan Parkway, Suite 2002 Durham, NC 27707. EPA/452/B-02-001; Section 6 - Particulate Matter Controls; Chapter 2 - Wet Scrubbers for Particulate Matter - July, 15 ${ }^{\text {th }} 2002$.

6. Harry J. White - Journal of the Air Pollution Control Association - ISSN: 0002-2470 Electrostatic Precipitation of Fly Ash - 1977. 